\title{
The Size of Anterior Fontanelle and Its Determinants at Birth Among Neonates in Northern Ethiopia: A Cross-Sectional Study
}

This article was published in the following Dove Press journal: Pediatric Health, Medicine and Therapeutics

\author{
Dawit Habte Woldeyes (D) \\ Mengstu Desalegn Kiros (D) \\ Belta Asnakew Abegaz (iD) \\ Ashenafi Abate Woya (iD) 2 \\ 'Anatomy Unit, Department of \\ Biomedical Sciences, College of Medicine \\ and Health Sciences, Bahir Dar \\ University, Bahir Dar, Ethiopia; \\ ${ }^{2}$ Department of Statistics, College of \\ Science, Bahir Dar University, Bahir Dar, \\ Ethiopia
}

Background: Fontanels are anatomical features of the infant human skull comprising any of the soft membranous gaps between the cranial bones that make up the calvaria of a neonate. Various factors are taught to be responsible for the differences in the size of the fontanel at birth. Accordingly, this study is performed to examine the size of the anterior fontanel, associated factors, and the clinical significance in Northern Ethiopia at birth.

Methods and Materials: A Cross-sectional study was conducted in a sample of 425 neonates. The data were analyzed using SPSS version 21. Descriptive and summary statistics were presented in the form of tables and figures. All the data were presented as mean \pm S.D. The association between dependent variables and independent variables was explored by using Pearson's chisquare test and logistic regressions. P-values $<0.05$ were considered to be statistically significant. Results: The mean anterior fontanel size for the study population was $3.07 \mathrm{~cm}$ with a $95 \%$ confidence interval $(3.00,3.14)$. For a unit increase of head circumference of a neonate, the odds of having abnormal fontanel increase by $52.6 \%$. Term neonates were $74.4 \%$ less likely to have abnormal fontanel size than preterm. Vaginally delivered neonates were $64.2 \%$ less likely to have abnormal fontanel size than neonates born by caesarean section. Low birth weight neonates were at risk of abnormal fontanel size. The odds ratio of the normal weight of neonate at birth was 0.327473 [95\%, CI, $(0.153364,0.6992422)]$.

Conclusion: Gestational age, mode of delivery, head circumference, and birth weight are the most important determinant factors associated with anterior fontanel size.

Keywords: fontanel, birth weight, gestational age, head circumference, mode of delivery

\section{Introduction}

The fontanelles are fibrous, membrane-covered gaps where more than two cranial bones are placed side by side. A newborn baby has six fontanelles: the anterior and posterior, two posterolateral, and two anterolateral. The anterior fontanelle is the most prominent, the most variable in size, and clinically important. ${ }^{1}$ It is diamond (rhomboid) shaped and located at the junction of the two parietal and two frontal bones. The superior sagittal dural venous sinus is partially situated beneath the anterior fontanel. ${ }^{2}$

Assessment of the size of the anterior fontanel is part of the routine examination of neonates. This assessment is done together with the head circumference measurement as an index of cranial development from birth and to the second year of life. $^{2-4}$ Despite the clinical value of examining the anterior fontanel, its measurement has not been routinely performed as part of the newborn examination. ${ }^{5,6}$
Correspondence: Dawit Habte Woldeyes $\mathrm{Tel}+251913214906$

Email dwthabte@gmail.com
Pediatric Health, Medicine and Therapeutics 2020:II 477-483 
The unusually large or small size of fontanel may indicate intracranial or system disorders. ${ }^{7-9}$ An unusually small fontanel may be secondary to brain growth retardation, craniosynostosis, ${ }^{10}$ or hyperthyroidism. ${ }^{7}$ A large fontanel with unincreased cranial pressure may be a feature of a variety of disorders, ${ }^{11}$ such as skeletal anomalies (eg, achondroplasia), ${ }^{8}$ cleidocranial dysostoses, ${ }^{12}$ osteogenesis imperfecta, ${ }^{13}$ chromosomal anomalies (eg, trisomies 9p, 13, $18,21),{ }^{11}$ hypothyroidism, ${ }^{9}$ or intrauterine malnutrition. ${ }^{14}$

Fontanel development is influenced by brain growth, dural attachments, suture development, and osteogenesis. ${ }^{15}$ Studies in different areas of the world indicated that several factors are thought to contribute to the variability of the anatomy of the anterior fontanel. The principal factors recognized as influencing anterior fontanel size are gestational age, ${ }^{4,16}$ gender, ${ }^{8,17-20}$ race, ${ }^{21-23,}$ and genetics. ${ }^{15}$ Even within a given country, geographical or regional differences in fontanelle sizes have been reported. ${ }^{22,24}$

Knowledge of the embryological development of fontanelles could lead to a better understanding of variations in fontanelles. This can be explained as follows:

The flat bones of the skull develop as part of the membranous neurocranium. Needle-like spicules radiate from a primary ossification center toward the periphery. These irregular bone islands are remodeled into flattened sheets of bones by osteoblast and osteoclast activity. During fetal and postnatal life, the membranous bones enlarged by resorption centrally and by the apposition of new layers at the edges of the sutures. Except for the metopic suture between the frontal bones, which closes at two years of age, the sutures remain open until brain growth ceases in the second year of life. ${ }^{25}$ Once a suture is fused, growth perpendicular to that suture is restricted. Therefore, fontanel size is influenced by brain growth, dural attachments, suture development, and osteogenesis. ${ }^{26,27}$

Thus, the knowledge of the size of the anterior fontanel is useful to evaluate the failure of calvarial and brain growth. The diagnosis of an abnormally large or small anterior fontanelle at birth must assume a knowledge of normal variations in its size. In Ethiopia, there are no satisfactory references in published reports about either the methods of measurement or the possible variations in the size of the anterior fontanelle concerning its determinants. Therefore, this study is conducted to investigate the size of the anterior fontanel, associated factors, and the clinical significance of the size in Northern Ethiopia. This enables to establish baseline values and relate the findings to some factors that affect fontanelle size.

\section{Methods and Materials}

A cross-sectional study design was employed with a random sample of 425 neonates at Felege Hiwot Referral Hospital in Bahir Dar; Ethiopia.

The sample size was calculated using a single population proportion formula $\mathrm{N}>10,000$ and a $95 \%$ confidence interval $(\mathrm{CI})$ with a marginal error of $5 \%$ and a $5 \%$ nonresponse rate.

\section{Data Collection Procedure}

The AF size measurement were taken with in the first 12 hours after the delivery. Before data collection, training on how to measure the size was given by gynecologists and pediatricians for nurses working in the data collection center. A pilot study was conducted before the main study.

After the researchers obtained written informed consent from each mother, data were collected using an observation checklist. Along with measuring the anterior fontanel, maternal sociodemographic variables, sex of the neonate, mode of delivery, name of health facility, gestational age, the residence of the mother, birth weight were recorded.

The data related to the conditions during delivery, maternal socio-demographic variables of labor, and mode of delivery of the neonate were obtained from the mother and attending clinicians and recorded. Birth weight, head circumference, and anterior-posterior and the transverse dimension of anterior fontanel were measured using nonelastic (non-stretchable) plastic tape. All measurements were in centimeter and gram. Neonates with a congenital malformation, obvious chromosomal abnormalities, abnormal presentation of labor, birth injury, asphyxia, persistent cyanosis, convulsions, cephalohematoma systemic illness, and eventful perinatal period were excluded from the study.

The birth weight of the neonate was measured using a balance beam neonate scale with the accuracy of the closest gram. According to previous studies, ${ }^{28}$ birth weight was recorded as low, if it measures less than $2500 \mathrm{~g}$; normal, when it was between $2500 \mathrm{~g}-4000 \mathrm{~g}$, and overweight, when it was greater than $4000 \mathrm{~g}$.

Since the shape of the anterior fontanel varies widely, there are various methods of measuring its size. A simple, repeatable, and practical method is needed to measure the size of anterior fontanelle if it is to be used in clinical practice. For example, in one study a marker pen was used 
to mark the corners on the scalp which was later transferred to a paper. In another study, it was measured with a caliper and the corners were marked with blunt ends. ${ }^{22}$ On the other hand, Popich and Smith marked the corners on the scalp with a colored pen and measured the distance using a steel tape. ${ }^{8}$ However, the researchers in the present study applied the most commonly used method developed by Kiesler and Ricer. The corner of the anterior fontanel was determined by inserting the index finger of the examiner to each corner, and was marked with a washable ink; then with a calibrated paper tape. The distance between the anterior and posterior points and between the transversal points was measured and recorded with an accuracy of \pm $1 \mathrm{~mm}$. The average of anterior-posterior diameter (length) and transverse diameter (width) is considered as the anterior fontanel size. The anterior fontanel is considered to be small if it is less than $0.6 \mathrm{~cm}$; normal if it is $0.6-3.6 \mathrm{~cm}$ and large fontanelle if it is greater than $3.6 \mathrm{~cm} .{ }^{1}$

Head circumference was measured with a narrow calibrated non-elastic plastic tape around the infant's head, through the prominence of the occiput to supraorbital ridges, with an accuracy of $\pm 1 \mathrm{~mm},{ }^{1,2,20}$ head circumference is small if it is less than $31 \mathrm{~cm}$; normal if it is between $31-37 \mathrm{~cm}$, and large if it is greater than $37 \mathrm{~cm} .{ }^{28}$

\section{Data Processing and Analysis}

The data obtained were checked for clarity, consistency, and completeness. The collected data were analyzed by SPSS version 21 . Descriptive and summary statistics were presented in tables, and figures. All the data were presented as mean $\pm \mathrm{S}$. D. The association between dependent and independent variables was explored using Pearson's chi-square test and Logistic regressions. P-values $<0.05$ were considered to be statistically significant.

\section{Results \\ General Information}

A total of 425 questionnaires by mothers of neonates were returned, which accounted for a $100 \%$ response rate. A total of 425 neonates were included in this study of which $329(77.4 \%)$ were born with the normal size of anterior fontanel while $96(22.6 \%)$ neonates were born with large anterior fontanel. The average size of the anterior fontanel was $3.07,95 \% \mathrm{CI}(3.0,3.15)$.

\section{Socio-Demographic Characteristics}

As displayed in Table 1 below, among the neonates, about half (ie $243(57.2 \%)$ ) were males and $182(42.8 \%)$ were females. About 111 (26.1\%) neonatal children were preterm, $278(65.4 \%)$ were normal gestational age and $36(8.5 \%)$ were post-term. In terms of residence, $266(62.6 \%)$ were urban residents. Regarding their mode of delivery: 242 (57.0\%) were vaginal, $358(84.2 \%)$ of the neonates have their birth weight were greater than 2.5 kilograms.

\section{Size of Anterior Fontanel}

The mean size of the anterior fontanel for the study population was $3.07 \mathrm{~cm}$ with a $95 \%$ confidence interval (3.00,

Table I Socio-Demographic Characteristics and Background Information of the Neonates

\begin{tabular}{|c|c|c|c|c|c|}
\hline & & \multirow[t]{2}{*}{ Frequency } & \multicolumn{2}{|l|}{ Fontanel Category } & \multirow[t]{2}{*}{ Chi-Square } \\
\hline & & & $0.6 I-3.6$ (Normal) & $>3.6$ & \\
\hline Sex of neonate & $\begin{array}{l}\text { Male } \\
\text { Female }\end{array}$ & $\begin{array}{l}243(57.2 \%) \\
182(42.8 \%)\end{array}$ & $\begin{array}{l}190(78.2 \%) \\
139(76.4 \%)\end{array}$ & $\begin{array}{l}53(21.8 \%) \\
43(23.6 \%)\end{array}$ & 0.658 \\
\hline Residence of the mother & $\begin{array}{l}\text { Rural } \\
\text { Urban }\end{array}$ & $\begin{array}{l}159(37.4 \%) \\
266(62.6 \%)\end{array}$ & $\begin{array}{l}124(78.0 \%) \\
205(77.1 \%)\end{array}$ & $\begin{array}{l}35(22.0 \%) \\
61(22.9 \%)\end{array}$ & 0.826 \\
\hline Gestational Age & $\begin{array}{l}<37 \text { (Preterm) } \\
37-42 \text { (Normal) } \\
>42 \text { (Poster) }\end{array}$ & $\begin{array}{l}\text { III (26.I\%) } \\
278(65.4 \%) \\
36(8.5 \%)\end{array}$ & $\begin{array}{l}66(59.5 \%) \\
233(83.8 \%) \\
30(83.3 \%)\end{array}$ & $\begin{array}{l}45(40.5 \%) \\
45(16.2 \%) \\
6(16.7 \%)\end{array}$ & 0.001 \\
\hline Birth Weight & $\begin{array}{l}\leq 2.5 \\
>2.5\end{array}$ & $\begin{array}{l}67 \text { (15.38\%) } \\
358(84.2 \%)\end{array}$ & $\begin{array}{l}46(68.7 \%) \\
283(79.1 \%)\end{array}$ & $\begin{array}{l}21 \text { (3I.3\%) } \\
75 \text { (20.9\%) }\end{array}$ & 0.002 \\
\hline Types of delivery & $\begin{array}{l}\text { Cesaring section } \\
\text { Vaginal } \\
\text { Other }\end{array}$ & $\begin{array}{l}159(37.4 \%) \\
242(57.0 \%) \\
24(5.6)\end{array}$ & $\begin{array}{l}125(78.6 \%) \\
187(77.3 \%) \\
17(70.8 \%)\end{array}$ & $\begin{array}{l}34(21.4 \%) \\
55(22.7 \%) \\
7(29.2)\end{array}$ & 0.001 \\
\hline
\end{tabular}




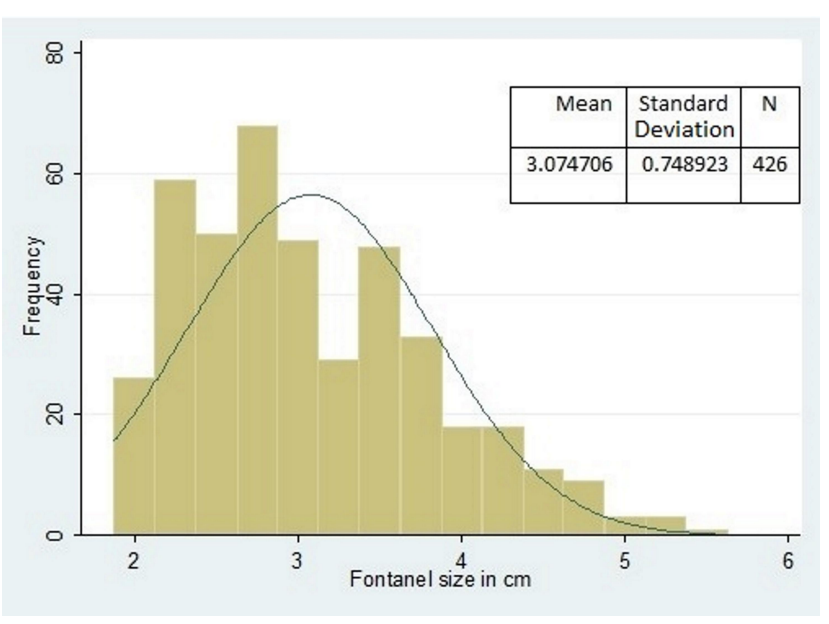

Figure I The distribution of Anterior fontanel size.

3.14) and the standard deviation (S.D.) of AF for the study was $0.75 \mathrm{~cm}$, (Figure 1). From the total neonates, 177 (41.6\%) had an anterior size between 2.01 and $2.88 \mathrm{~cm}$. The second large proportion (ie 159 (37.4\%)) of them had anterior fontanel size between 2.89 and 3.75. The remaining $16(3.8 \%)$ of them had anterior fontanel size between 4.64 and 5.50. Based on the percentile distribution, 77.4\% of neonates had an anterior fontanel size below $3.6 \mathrm{~cm}$ (Table 2).

The result of this study showed that the maximum value analog of Cook's influence statistics and DFBETA for each predictor variable were less than 1.0. Therefore, there is no potential influential observation. In addition to this, the minimum value of VI was 0.00217 , and the maximum value was calculated as 0.19737 , which indicated that there were no predictor variables VIF $>5$. Thus, there is no severe co-linearity among predictor variables.

The assessment of the overall model evaluation and goodness of fit test was a good indicator. Based on Hosmer and Lemeshow test $\mathrm{x}^{2}=8.56$ with an 8-degree freedom level of significance was 0.318 witches implicit that the data was a good fit for the model. The statistical tests of

Table 2 The Frequency Distribution of the Size of the Anterior Fontanel

\begin{tabular}{|l|l|l|}
\hline Fontanel Size & Frequency & Percent \\
\hline$\leq 2.00$ & 26 & 6.1 \\
$2.01-2.88$ & 177 & 41.6 \\
$2.89-3.75$ & 159 & 37.4 \\
$3.76-4.63$ & 47 & 11.1 \\
$4.64-5.50$ & 16 & 3.8 \\
Total & 425 & 100.0 \\
\hline
\end{tabular}

individual predictors were conducted to identify the associated risk factors with the size of the fontanel. Results shown in Table 3 revealed that the mode of delivery, birth weight, head circumference, and gestational age were significantly associated with the size of anterior fontanel. The other potential risk factors such as sex and residence did not significantly associate with fontanel size.

The neonatal head circumference is significantly associated with fontanel size. For a unit increase of head circumference of a neonate, the odds of having abnormal fontanel increase by $52.6 \%$.

The gestational age of a mother was a significant risk factor for the fontanel size of the neonate. Neonates who were born at normal gestational age were $74.4 \%$ less likely to have abnormal fontanel size than neonates whose gestational period was preterm. Neonates, whose gestational period was post-term were $74.1 \%$ less likely to have abnormal fontanel size than neonate children whose gestational period was preterm.

The mode of delivery was significantly associated with the fontanel status of the neonates $(p<0.05)$. Neonates whose delivery type was vaginal were $64.2 \%$ less likely to had abnormal fontanel size than neonates whose delivery type was Caesarean.

The birth weight of neonates at birth was a significant factor for fontanel size. Neonates with low birth weight were more likely to have a risk of abnormal fontanel size. The odds ratio of the normal weight of neonate at birth was 0.327473 [95\%, CI, $(0.153364,0.6992422)]$. Neonates who were underweight at birth were $32.7 \%$ more likely to have large fontanel than neonates who were not underweighted.

\section{Discussions}

This health institution-based study was conducted with an attempt to identify the size and determinants of neonatal anterior fontanel size in the city of Bahir Dar. The size of the anterior fontanel varies according to gestational age, ${ }^{4,16}$ gender, ${ }^{8,17-20}$ race, ${ }^{21-23}$ and genetics. ${ }^{15}$ Even within a given country, the role of geographical or regional differences for variations in fontanelle size has been reported. ${ }^{22,24}$ However, an Israeli report, noted that there is no difference between children of diverse ethnic origins in their study population. ${ }^{19}$ On the first day of life, the normal fontanel ranges from $0.6-3.6 \mathrm{~cm}$, with a mean of $2.1 \mathrm{~cm} .{ }^{8}$ Black infants have larger fontanels $(1.4 \mathrm{~cm}$ to $4.7 \mathrm{~cm}){ }^{21}$ Anterior fontanels tend to close earlier in boys than in girls; the initial size of the fontanel is not a predictor of when it will close. ${ }^{4}$ 
Table 3 Logistic Regression Results of the Incidence of the Size of the Anterior Fontanel

\begin{tabular}{|c|c|c|c|c|c|c|c|}
\hline Variables & Categorized & Odds Ratio & Std. Err. & $\mathbf{z}$ & $\mathbf{P}>\mathbf{z}$ & [95\% Conf.] & [Interval] \\
\hline \multirow[t]{2}{*}{ Sex } & \multicolumn{7}{|l|}{ Male } \\
\hline & Female & 1.406789 & 0.371967 & 1.29 & 0.197 & 0.8378449 & 2.362078 \\
\hline \multirow[t]{3}{*}{ Gestational age } & \multicolumn{7}{|l|}{ Preterm } \\
\hline & Normal & $0.256485 \mathrm{I}$ & 0.075177 & -4.64 & 0.000 & 0.1444004 & $0.45557 \mid$ \\
\hline & Post term & 0.2596683 & 0.138675 & -2.52 & 0.012 & 0.0911668 & 0.7396069 \\
\hline \multirow[t]{2}{*}{ Residence } & \multicolumn{7}{|l|}{ Rural } \\
\hline & Urban & $1.490 \mid 45$ & 0.418785 & 1.42 & 0.156 & 0.8590319 & 2.584922 \\
\hline \multirow[t]{2}{*}{ Birth weight } & \multicolumn{7}{|c|}{ Underweight (<2.5 gram) } \\
\hline & $\begin{array}{l}\text { Normal }(\geq 2.5 \\
\text { gram) }\end{array}$ & 0.327473 & 0.126746 & -2.88 & 0.004 & 0.153364 & 0.6992422 \\
\hline $\begin{array}{l}\text { Head } \\
\text { Circumference }\end{array}$ & & 1.526323 & 0.125930 & 5.13 & 0.000 & 1.298428 & 1.794219 \\
\hline \multirow[t]{3}{*}{ Delivery Type } & \multicolumn{7}{|l|}{ Caesarian } \\
\hline & Vaginal & 0.358723 & 0.098549 & -3.73 & 0.000 & 0.2093706 & $0.6|46| 46$ \\
\hline & Other & 0.99637 & 0.519120 & -0.01 & 0.994 & 0.3588677 & 2.766349 \\
\hline _cons & & $7.7 \mid \mathrm{e}-07$ & $20.16 \mathrm{e}-06$ & -5.02 & 0.000 & $3.18 \mathrm{e}-09$ & 0.0001869 \\
\hline
\end{tabular}

In the present study, the mean anterior fontanel size for the study population was $3.07 \mathrm{~cm}$ with a $95 \%$ confidence interval $(3.00,3.14)$. Another study that was done in Gondar, Ethiopia revealed that the mean size of anterior fontanelle in term neonates was $3.00 \pm 0.62 \mathrm{~cm}$ (range $1.70-5.50 \mathrm{~cm})^{29}$

Anterior fontanel size is affected by region (ethnicity). In a study done in India, the mean size of anterior fontanel at different age intervals was higher as compared to the Western and few Indian studies. ${ }^{5}$ Another study done in Iran indicates that anterior fontanel size was found to be smaller than those reported for American and Nigerian infants, and larger than Scottish and Israeli infants. ${ }^{20}$ A study done in Nigeria revealed that ethnic origin significantly affected the size of anterior fontanel. ${ }^{29}$

Gender difference is controversial on anterior fontanel size. A study in Iran shows there is a significant difference in anterior fontanel size between genders, $26.70 \pm 13.29 \mathrm{~mm}$ in boys, and $23.67 \pm 13.20 \mathrm{~mm}$ in girls. ${ }^{20}$ This Iranian finding is similar to our study which states that the potential risk factors such as sex of the neonate and residence were not significantly associated with fontanel size. However, other studies reported that there is no significant difference in the anterior fontanel size with gender difference. For example, a study done in Nigeria indicates the male and female neonates had comparable anterior fontanel sizes of $2.97 \pm 0.67$ and 2.98 $\pm 0.75 \mathrm{~cm}$, respectively. This shows that there is no significant difference $(\mathrm{p}=0.89)$; $95 \%$ confidence interval $-0.18-0.16 .^{2,4}$ According to research conducted in China, there were no anterior fontanel size variations based on gender differences $(p>0.05)$. And the size of the anterior fontanel was not correlated with weight, length, and head circumference $(\mathrm{p}>0.05){ }^{6}$

Anterior fontanel size can vary with the mode of delivery. In this study, the mode of delivery of neonate was significantly associated with the fontanel status of children $(\mathrm{p}<0.05)$. Neonates whose delivery type was vaginal were $64.2 \%$ less likely to exhibit abnormal fontanel size than neonates whose delivery type was Caesarean (Table 3). On the other hand, a Nigerian study revealed that there was no statistically significant difference between the anterior fontanel sizes of babies delivered by cesarean section and those delivered vaginally ( $\mathrm{p}=0.262$ ), No difference was found in the anterior fontanel between the types of delivery in a study done in Iran. $^{2,20}$ 
Gestational age needs to be considered during anterior fontanel size evaluation. The findings of the present study reveal that neonates who were born at normal gestational age were $74.4 \%$ less likely to have abnormal fontanel size than neonates whose gestational period was preterm (Table 3). Studies done in India and Indonesia indicate that there was no significant difference between full-term and preterm infants in anterior fontanel size $(\mathrm{p}=0.280) .{ }^{1,2,27}$ In another study done in England and Switzerland, the anterior fontanelle enlarges with advancing gestation with the mean value for the preterm (33-36 weeks) infants is higher than that of the more immature preterm (28-32 weeks) group, but the difference is not significant ( $p>$ $0.05)$. The mean value for anterior fontanelle size in the term infants is also higher than that of the preterm infants (33-36 weeks). Again, the difference is not significant ( $p$ $>005)$. The difference between the preterm (28-32 weeks) and the term infants is significant $(\mathrm{p}<001) .{ }^{4,16}$

This study revealed that neonatal head circumference was significantly associated with the fontanel size. For a unit increase of head circumference of a neonate, the odds of having abnormal fontanel was increased by $52.6 \%$. This finding is supported by other studies. For example, in a study done in Indonesia, there was a significant difference in head circumference between full-term and preterm infants $(\mathrm{p}<0.001)(27)$. On the other hand, in a study done in Nigeria, the anterior fontanel size of newly born babies showed no significant correlation with the head circumference. . $^{2,4,17,23,30}$

In this study, the weight of neonates at birth was a significant factor of fontanel size. Low birth weight neonates were more likely to encounter a risk of abnormal fontanel size. The odds ratio of the normal weight of neonate at birth was 0.327473 [95\%, CI, (0.153364, 0.6992422)]. Neonates who were underweight at birth were $32.7 \%$ more likely to have fontanel size than neonates who were not underweight. However, a study done in Nigeria and Indonesia indicates there is no significant difference between anterior fontanelle size and body weight. $2,23,27,30$

\section{Conclusions}

Gestational age, delivery type, head circumference, and birth weight are the most important determinant factors associated with anterior fontanel size. An abnormal fontanel in an infant can indicate a serious medical condition. Measuring and reporting the size of anterior fontanel should be a routine clinical practice in health institutions. Consultation with a pediatric neurosurgeon should be considered if the diagnosis or presence of an abnormality is unclear.

\section{Recommendations}

Since Anterior fontanelle size varies according to race, geographical variations and Ethiopia is a land of different ethnicities and various geographical locations, further studies should be conducted to identify other correlates of the fontanel size that are not analyzed in this study.

\section{Data Sharing Statement}

The datasets used and analyzed during this study are available from the corresponding author on reasonable request.

\section{Ethics Approval and Consent to Participate}

This study was conducted in accordance with the Declaration of Helsinki. Before conducting the study, the study protocol was reviewed and approved by the institutional Ethical Review Committee of Bahir Dar University. A letter of permission was obtained from the heads of the health institutions. Written consent was obtained from the study participants and/caregivers. Besides, the right of withdrawal from the study was assured at any time during data collection. Confidentiality was maintained at all levels of the study.

\section{Acknowledgments}

The authors are grateful to all students at Bahir Dar University who participated in this study. The authors are also grateful to all data collectors participating in this research.

\section{Author Contributions}

All authors made a significant contribution to the work reported, whether that is in the conception, study design, execution, acquisition of data, analysis and interpretation, or in all these areas; took part in drafting, revising or critically reviewing the article; gave final approval of the version to be published; have agreed on the journal to which the article has been submitted; and agree to be accountable for all aspects of the work.

\section{Funding}

There is no funding to report.

\section{Disclosure}

The authors report no conflicts of interest for this work. 


\section{References}

1. Kiesler J, Ricer R. The abnormal fontanel. Am Fam Physician. 2003;67(12):2547-2552.

2. Uzukwu-Edeani $\mathrm{CV}$, Ibeziako $\mathrm{SN}$, Ikefuna $\mathrm{AN}$, Uchendu UO. Normal anterior fontanelle sizes in newborn Igbo babies in South-Eastern Nigeria. S Afr J Child. 2013;7(2):50. doi:10.7196/ sajch.516

3. Malas M, Sulak O. Measurements of anterior fontanelle during the fetal period. J Obstet Gynaecol. 2000;20(6):601-605. doi:10.1080/ 01443610020001431

4. Duc G, Largo RH. Anterior fontanel size and closure in term and preterm infants. J Pediatr. 1986;78(5):904-908. PMID: 3763303.

5. Swaiman KF, Ashwai S, Ferriero DM. Pediatric Neurology: Principles and Practice. 4th ed. Vol. 2. Philadelphia: Mosby; 2006 $2672 \mathrm{p}$.

6. Volpe JJ. Neurology of the Newborn. 4th ed. W.B. Saunders Company; 2001.

7. Robinson DC, Hall R, Munro DS. Grave's disease, an unusual complication: raised intracranial pressure due to premature fusion of skull sutures. Arch Dis Child. 1969;44(234):252-257. doi:10.1136/ adc. 44.234 .252

8. Popich GA, Smith DW. Fontanels: a range of normal size. $J$ Pediatr. 1972;80(5):749-752. doi:10.1016/S0022-3476(72)80125-2

9. Smith DW, Popich G. Large fontanels in congenital hypothyroidism: A potential clue toward earlier recognition. J Pediatr. 1972;80 (5):753-756. doi:10.1016/S0022-3476(72)80126-4

10. Freeman JM, Craniostenosis BS. Review of the literature and report of thirty-four cases. Pediatrics. 1962;30:57-70.

11. Jones KL, Jones MC, Campo MD. Smith's Recognizable Patterns of Human Malformation: Expert Consult - Online and Print. 7th ed. Philadelphia, PA: Saunders; 2013:1016.

12. Forland M. Cleidocranial dysostosis: a review of the syndrome and report of a sporadic case, with a hereditary transmission. Am J Med. 1962;33(5):792-799. doi:10.1016/0002-9343(62)90256-5

13. McKusick VA. Heritable disorders of connective tissue. $J$ Chronic Dis. 1955;2(5):491-499. doi:10.1016/0021-9681(55)90148-X

14. Philip AGS. Fetal growth retardation: femurs, fontanels, and follow-up. Pediatrics. 1978;62(4):446-453.

15. Melnick M, Myrianthopoulos NC, Christian JC. Estimates of genetic variance for anterior fontanelle development in the NCPP twin population. Acta Genet Med Gemellol: Twin Res Hum Genet. 1980;29(2):151-155. doi:10.1017/S0001566000008631
16. Davies DP, Ansari BM, Cooke TJ. Anterior fontanelle size in the neonate. Arch Dis Child. 1975;50(1):81-83. PMID: 1124948. doi:10.1136/adc.50.1.81

17. Tan KL. Wide Sutures and large fontanels in the newborn. Am J Dis Child. 1976;130(4):386-390. PMID: 1266823. doi:10.1001/ archpedi.1976.02120050044007

18. Mir NA, Weislaw R. Anterior fontanelle size in Arab children: standards for appropriately grown full-term neonates. Ann Trop Pediatr. 1988;8(3):184-186. doi:10.1080/02724936.1988.11748566

19. Srugo I, Berger A. Anterior fontanelle size in healthy Israeli newborn infants. Isr J Med Sci. 1987;23(11):1137-1139.

20. Rashidi-Ranjbar N, Shajari H, Ashrafi M. Anterior fontanelle size in healthy iranian neonates on the first day of life. Acta Med Iran. 2011:49:543-546.

21. Faix RG. Fontanelle size in black and white term newborn infants. J Pediatr. 1982;100(2):304-306. doi:10.1016/S0022-3476(82)806616

22. Mattur S, Kumar R, Mathur GP, Singh VK, Gupta V, Tripathi VN. Anterior fontanel size. Indian Pediatr. 1994;31:161-164.

23. Ogunye O, Ikeji M, Adeodu O. Craniofacial dimensions in the African neonate. Nigerian J Pediatr. 1982;9:21-25.

24. Chakrabarti K. Anterior fontanel size in hilly and non-hilly newborns in and around the district of Darjeeling. Indian Pediatr. 1989;26 (1):41-44

25. Singh V. Textbook of Clinical Embryology. 2nd ed. Elsevier India; 2017:348.

26. Liptak G, Serletti J. Pediatric approach to craniosynostosis. Pediatr Rev. 1998;19:352. doi:10.1542/pir.19-10-352

27. Tiansyah RA, Mangunatmadja I, Pulungan AB. Head circumference and anterior fontanel measurements in newborns. Paediatr Indones. 2012;52(3):145. doi:10.14238/pi52.3.2012.145-51

28. Oumer M, Guday E, Teklu A, Muche A. Anterior fontanelle size among term neonates on the first day of life born at University of Gondar Hospital, Northwest Ethiopia. Uthman O, editor. PLoS One. 2018;13(10):1-13. doi:10.1371/journal.pone.0202454

29. Okorie EMC, Opara PI, Alikor EAD, Akani NA. Variations in anterior fontanel sizes in Nigerian children in Port Harcourt Metropolis. J Pediatr Neonatal Care. 2018;8(1):00306.

30. Adeyemo AA, Omotade OO. Variation in fontanelle size with gestational age. Early Hum Dev. 1999;54(3):207-214. doi:10.1016/S0378 3782(98)00089-9
Pediatric Health, Medicine and Therapeutics

\section{Publish your work in this journal}

Pediatric Health, Medicine and Therapeutics is an international, peerreviewed, open access journal publishing original research, reports, editorials, reviews and commentaries. All aspects of health maintenance, preventative measures and disease treatment interventions are addressed within the journal. Practitioners from all disciplines are invited to submit their work as well as healthcare researchers and patient support groups. The manuscript management system is completely online and includes a very quick and fair peer-review system. Visit http://www.dovepress.com/testimonials.php to read real quotes from published authors. 